\title{
Interaction of Ionic Liquids with Lipid Bilayer: A Biophysical Study of Ionic Liquid Cytotoxicity
}

\author{
Benxin Jing, ${ }^{\mathrm{a}, \mathrm{c}}$ Nan Lan, ${ }^{\mathrm{a}}$ Jie Qiu, ${ }^{\mathrm{b}}$ and Yingxi $\mathrm{Zhu}{ }^{\mathrm{a}, \mathrm{c}, *}$ \\ a Department of Chemical and Biomolecular Engineering, ${ }^{b}$ Department of Civil and \\ Environmental Engineering and Earth Sciences, University of Notre Dame, Notre Dame, Indiana \\ 46556, USA \\ ${ }^{\mathrm{c}}$ Department of Chemical Engineering and Materials Science, Wayne State University, Detroit, \\ Michigan 48202, USA
}

Electronic Supplementary Information (ESI)

Figure S1. Time evolution of the morphological change of $\alpha$-PC SLB with added a) $1.0 \mathrm{M}$ $\left[\mathrm{C}_{4} \mathrm{MIM}\right] \mathrm{Cl}$, b) $0.1 \mathrm{M}\left[\mathrm{C}_{6} \mathrm{MIM}\right] \mathrm{Cl}$, c) $0.01 \mathrm{M}\left[\mathrm{C}_{8} \mathrm{MIM}\right] \mathrm{Cl}$, and d) $0.001 \mathrm{M}\left[\mathrm{C}_{12} \mathrm{MIM}\right] \mathrm{Cl}$. Elapsing time is marked on the top of each fluorescence micrographs. Circled areas indicate the evolution of IL-lipid aggregates: flat domains (multilayer) was formed first, then wrap themselves up to form vesicles, and finally detach from $\alpha$-PC SLB to bulk solution, leaving their network footprint on the SLB. 


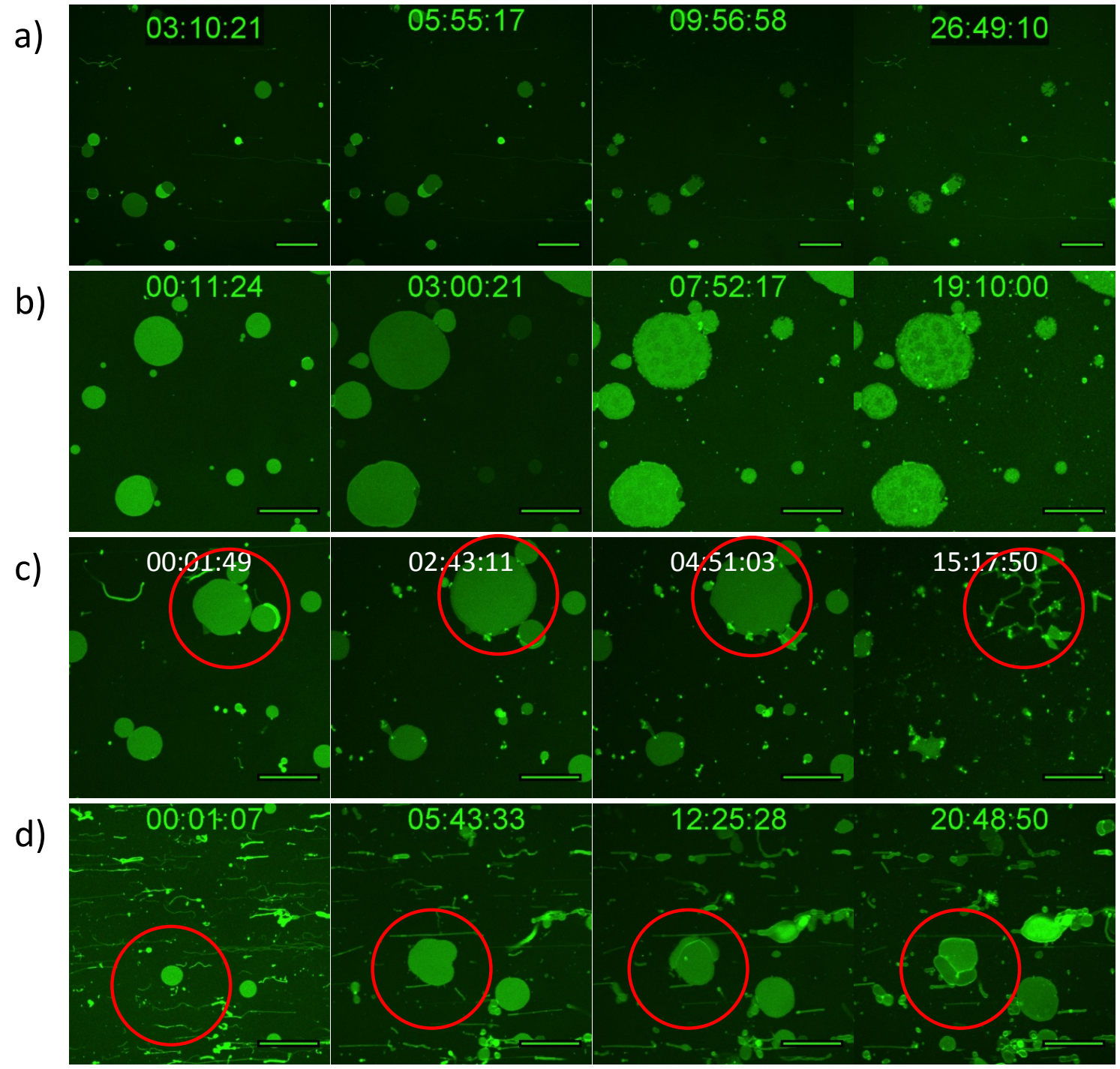


Figure S2. Three-dimensional morphological structure of $\alpha$-PC SLB acquired by confocal laser scanning microscopy $18 \mathrm{~h}$ after adding $0.001 \mathrm{M}\left[\mathrm{C}_{12} \mathrm{MIM}\right] \mathrm{Cl}$ in PBS. $\left[\mathrm{C}_{12} \mathrm{MIM}\right] \mathrm{Cl}$-induced lipid aggregates atop SLB in the forms of vesicles and multilayer are circled in yellow and red, respectively. The scale bar is $20 \mu \mathrm{m}$.

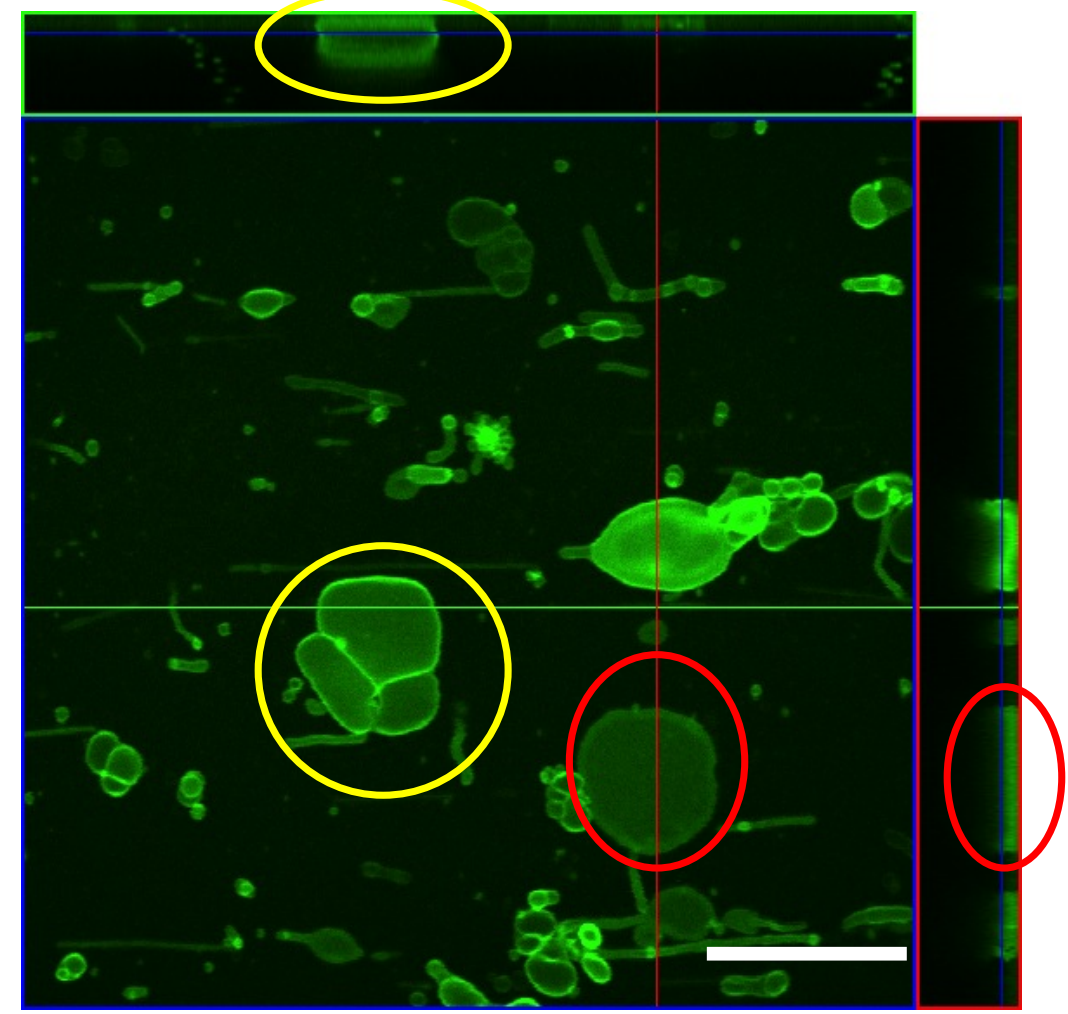


Figure S3. Morphological change of $\alpha$-PC SLB with added a) $\left[\mathrm{C}_{4} \mathrm{MIM}\right]\left[\mathrm{NTf}_{2}\right]$, b) $\left[\mathrm{C}_{8} \mathrm{MIM}\right]\left[\mathrm{NTf}_{2}\right]$ and c) $\left[\mathrm{C}_{12} \mathrm{MIM}\right]\left[\mathrm{NTf}_{2}\right]$ [NTf 2 of increased concentrations in PBS. All the fluorescence micrographs were acquired $60 \mathrm{~min}$ after adding each ILs of a given concentration marked on the top of each image. All the scale bars are $20 \mu \mathrm{m}$.

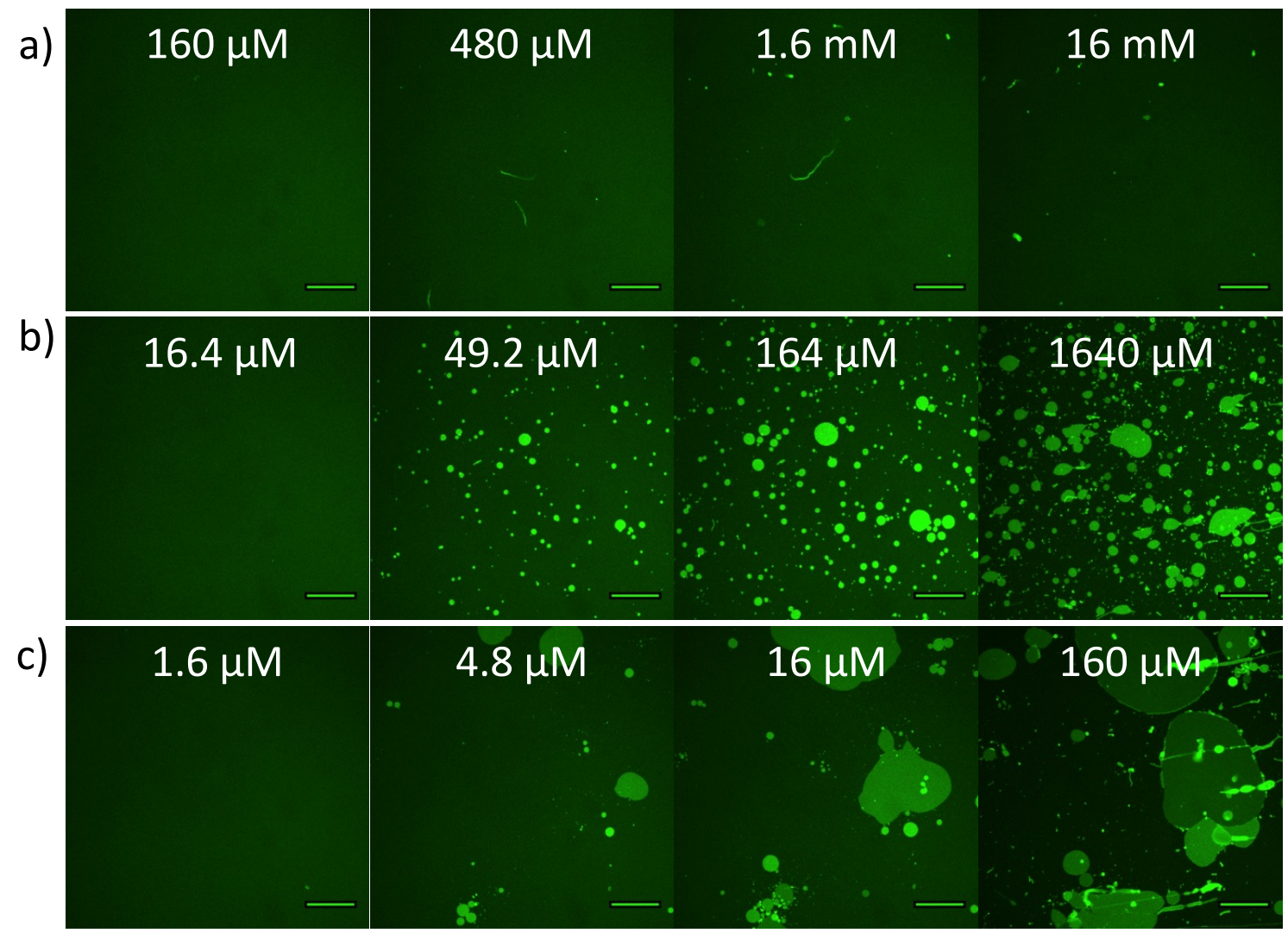


Figure S4. Measured hydrodynamic diameter of $\alpha$-PC SUVs with added ILs by dynamic light scattering: a) Effect of $\left[\mathrm{C}_{6} \mathrm{MIM}\right] \mathrm{Cl}$ (squares) and $\left[\mathrm{C}_{8} \mathrm{MIM}\right] \mathrm{Cl}$ (circles) concentration before the disruption of SUVs, b) Disruption of SUVs against elapsed time immediately after adding 10 $\mathrm{mM}\left[\mathrm{C}_{12} \mathrm{MIM}\right] \mathrm{Cl}$.
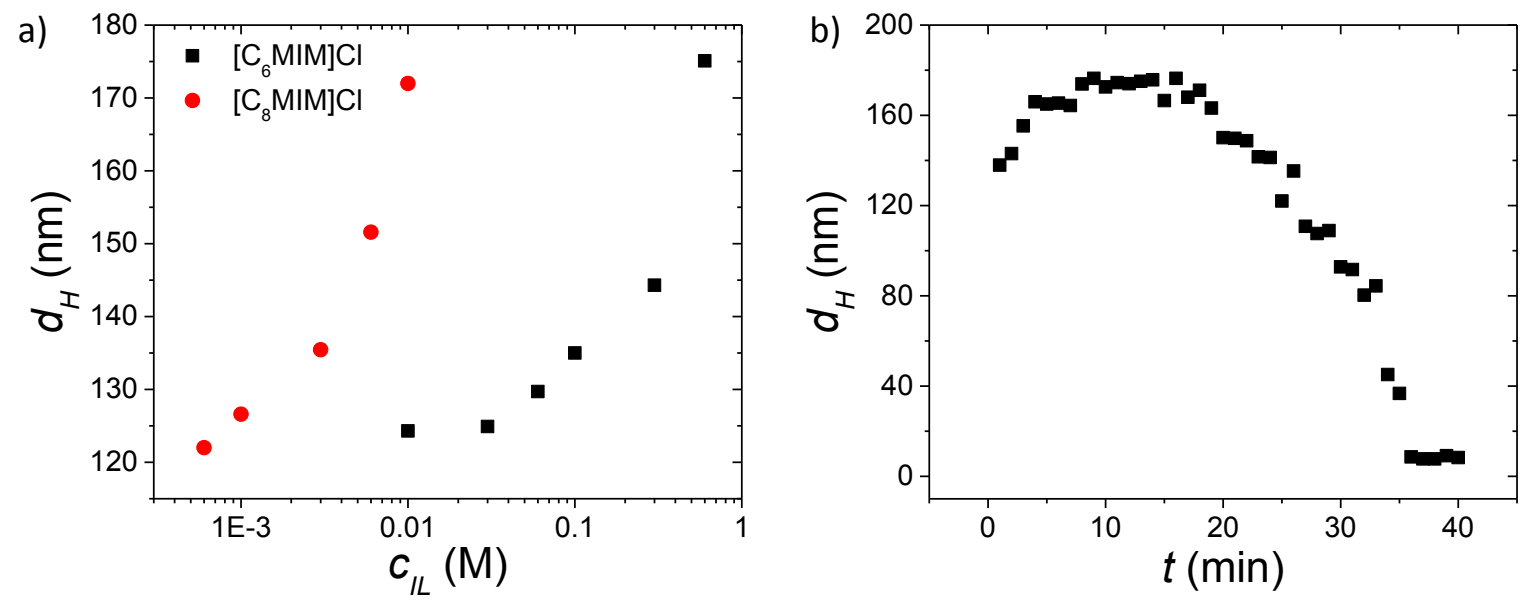

Figure S5. Effect of IL anions on the structure of $100 \mathrm{~g} / \mathrm{L} \alpha-\mathrm{PC} \mathrm{MLV}$ in PBS. The intensity profile of small angle X-ray scattering (SAXS) of $\alpha$-PC MLV without and with added a) $\left[\mathrm{C}_{8} \mathrm{MIM}\right] \mathrm{Cl}$ and b) $\left[\mathrm{C}_{8} \mathrm{MIM}\right]\left[\mathrm{NTf}_{2}\right]$. All the fresh MLV samples were prepared by mixing $\alpha-\mathrm{PC}$ with ILs in chloroform first, then dried and hydrated in PBS before the SAXS measurements.
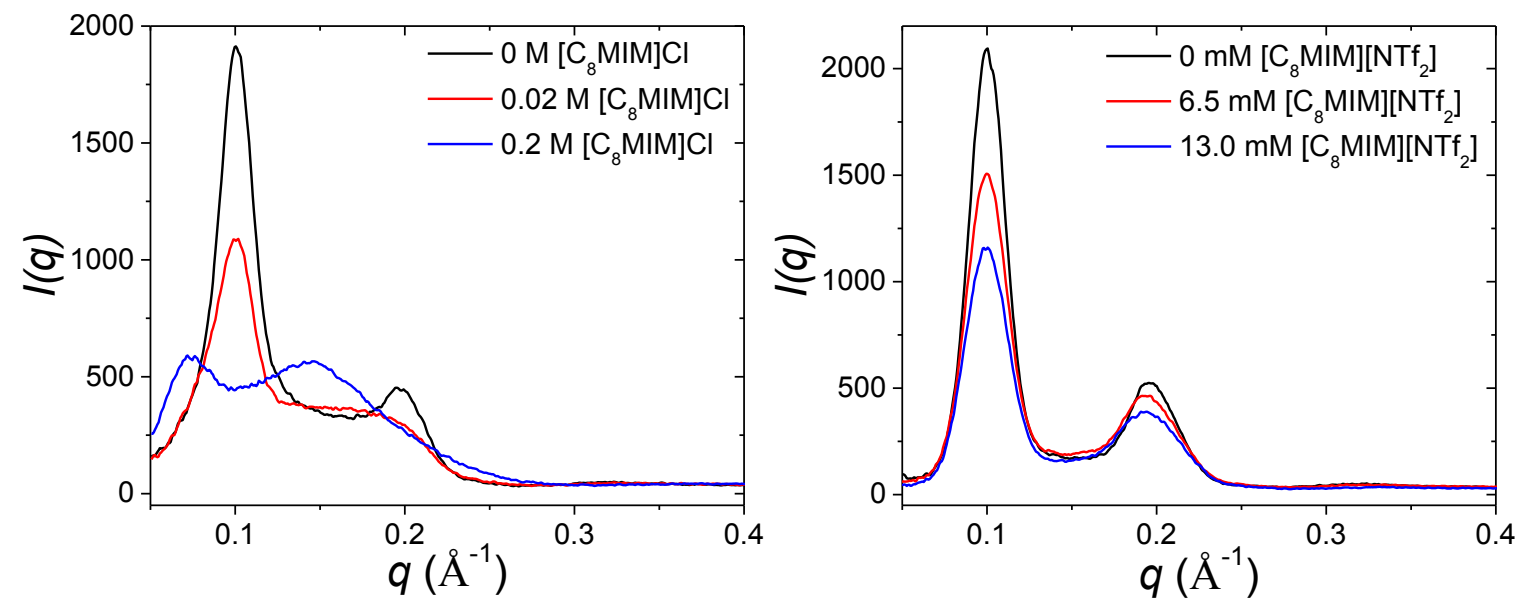
Figure S6. Autocorrelation curves of fluorescence probes, Alexa Flour 488 (squares) and R18 (circles), in $100 \mathrm{~g} / \mathrm{L} \alpha-\mathrm{PC}$ in $2.5 \mathrm{M}\left[\mathrm{C}_{6} \mathrm{MIM}\right] \mathrm{Cl} / \mathrm{PBS}$ solution measured by fluorescence correlation spectroscopy (FCS). The diffusion coefficient, D and the time-averaged concentration, $\langle c\rangle$, of fluorescent probe in $\alpha-P C$ is thus determined by fitting $\mathrm{G}(\tau)$ with the threedimensional Gaussian equation, $G(\tau)=\left(\pi^{\frac{3}{2}} \omega_{\mathrm{xy}}^{2} \omega_{\mathrm{z}}\langle\mathrm{c}\rangle\right)^{-1}\left(1+\frac{4 \mathrm{D} \tau}{\omega_{\mathrm{xy}}^{2}}\right)^{-1}\left(1+\frac{4 \mathrm{D} \tau}{\omega_{\mathrm{z}}^{2}}\right)^{-\frac{1}{2}}$ as shown in solid lines.

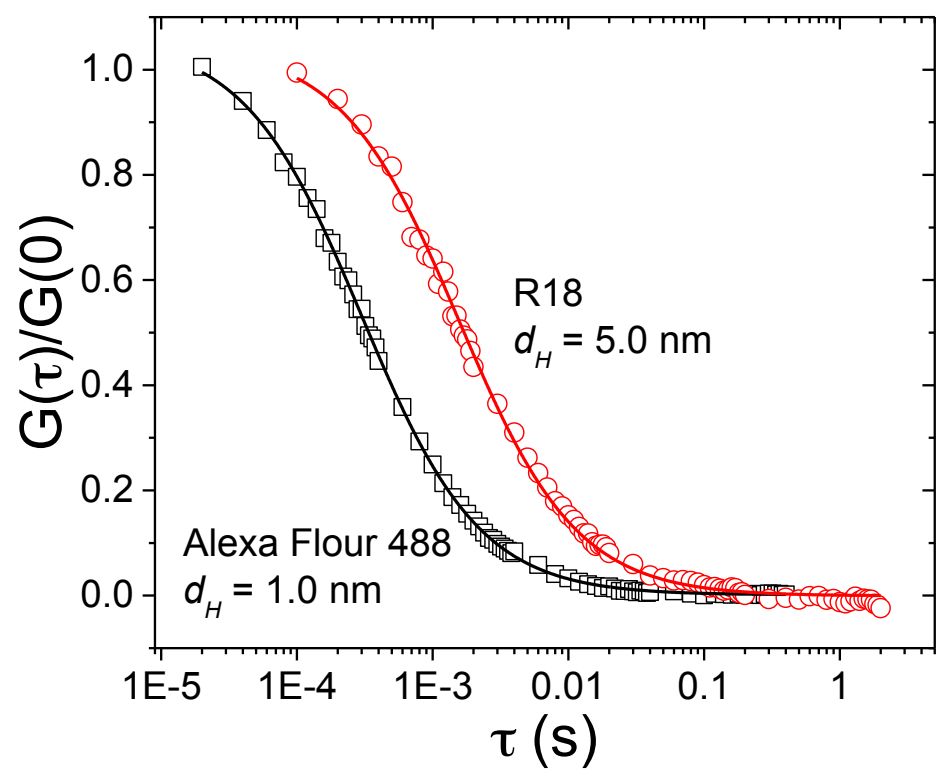


Figure S7. Digital photographs of $100 \mathrm{~g} / \mathrm{L} \alpha-\mathrm{PC}$ MLV with added ILs, confirming the clear suspension of dispersed IL-added MLVs. From left to right: no added ILs, added with $2.5 \mathrm{M}$ $\left[\mathrm{C}_{6} \mathrm{MIM}\right] \mathrm{Cl}$ and $0.5 \mathrm{M}\left[\mathrm{C}_{8} \mathrm{MIM}\right] \mathrm{Cl}$.
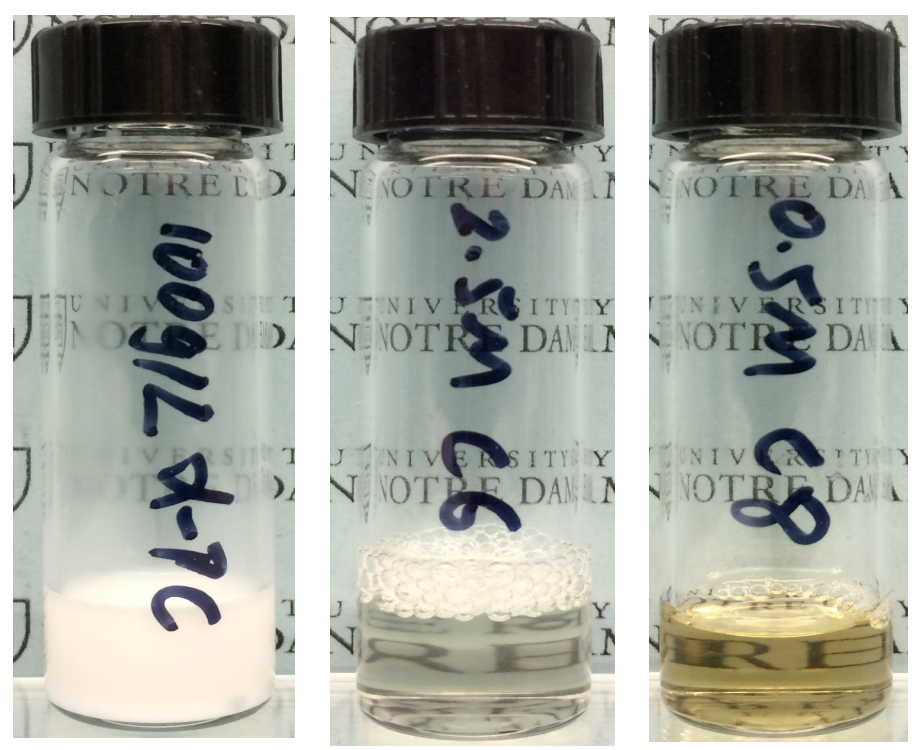